\title{
mejora de las condiciones de trabajo en los hornos hoffmann y aumento de la producción
}

\author{
(Ein Weg zur Verbesserung der Arbeitsbedingungen in Ringōfen der \\ keramischen Industrie und \\ zur Erzielung einer Leistungssteigerung)
}

W. RICHTER, W. HÖINGHAUS

עe: «1e Zlegelinaustrlen, vol. Y. num. 1z, funio 1956, pag. 440

\begin{abstract}
Los autores proponen una instalación móvil de climatizaclón, con objeto de refrigerar las cámaras en las que se va a proceder a retirar las piezas cerámicas cocldas. Mediante un ventilador se distribuye, por toda la sección de la cámara, una niebla artificial producida por atomización de agua. Este agua se evapora rápldamente, elevando el grado de humedad del aire, al mismo tiempo que la temperatura desciende bruscamente.
\end{abstract}

El aparato, en conjunto, consta de un ventilador, con una hélice de $400 \mathrm{~mm}$, acoplada directamente a un motor de $0,5 \mathrm{cV}$, de 1.400 r.p.m.; en estas condlciones el desplazamiento de alre es de $65 \mathrm{~m}^{3} / \mathrm{min}$. Las cuatro boquillas de atomización se encuentran dirigiđas de modo que los chorros se reúnan en un punto determinado de la caja del ventilador; dichas boqulllas se alimentan por tubos de $3 / 8$ pulgada $(0,95 \mathrm{~mm})$. La presión del agua debe ser, como mínimo, de 3 at. Se ha de disponer un filtro, fácil de limpiar, que detenga todo aquello que pueda obturar las boquillas.

El sistema posee una libertad de giro vertical de $30^{\circ}$ por enctma y por debajo de la horizontal; además, puede dar una vuelta completa en el plano horizontal. El aparato en cuestión se encuentra dispuesto sobre un bastidor, provisto de tres ruedas, que puede desplazarse rápldamente en un espacio reducido. Si no se dispone de ninguna conducción de agua en las proximídades del horno, el bastiđor puede llevar un pequeño depósito.

La cantidad de agua inyectada es de $20 \ldots 2 \mathrm{l} / \mathrm{h}$, según la temperatura y la humedad de la cámara; esta pulverización de agua no ejerce ninguna influencia sobre la marcha del horno ni sobre la atmósfera que all relna.

En un horno Hoffmann, calentado por gas, las cámaras que se iban a vaciar tenían una humedad relativa de 4 por 100 , y su temperatura era de $77^{\circ} \mathrm{C}$, lo cual hacia muy penoso el trabajo de los peones. Desde hace un año, que se empezó a utilizar este dispositivo, se mantiene una humedad relativa de $50 \ldots 60$ por 100 , que determina unas condiciones de trabajo más agradables. Se ha conseguldo, asi, que el rendimiento de los peones se eleve considerablemente, sin necesidad de esfuerzos suplementarios, y se ha logrado que incluso la veloctdad de avance del fuego sea un 20 por 100 superior.

En un caso particular, en que se trataba de realizar una separación sin que disminuyese la producción, la climatizactón ha permitido vaciar cinco cámaras, una después de la otra, cosa que hublera sido imposible si no se hubiese dispiesto de esta instalación.

S. F.S. 